Journal of Advanced Research in Fluid Mechanics and Thermal Sciences

Journal homepage: www.akademiabaru.com/arfmts.html ISSN: 2289-7879

\title{
Exergy and Energy Analyses of Dual-Temperature Evaporator Split AC System Incorporated A Capillary Tube and A Two- Phase Ejector
}

\author{
Made Ery Arsana ${ }^{1,2}$, I Gusti Bagus Wijaya Kusuma ${ }^{1}$, Made Sucipta ${ }^{1}$, I Nyoman Suamir2,* \\ Study Program of Doctoral Engineering Science, Faculty of Engineering, Udayana University, Denpasar City Campus, Bali, Indonesia \\ Department of Mechanical Engineering of Politeknik Negeri Bali, Bukit Jimbaran, Bali, Indonesia
}

ARTICLE INFO ABSTRACT

\section{Article history:}

Received 30 March 2020

Received in revised form 10 June 2020

Accepted 14 June 2020

Available online 4 November 2020

\section{Keywords:}

\begin{abstract}
This study was aimed to investigate performance of a split type air conditioning (SAC) system applying exergy destruction method. A numerical model was established based on exergy destruction analysis of a Condenser Outlet Split-Split Air Conditioning (COSSAC) system integrated with dual-temperature evaporator and incorporated capillary tube and ejector as expansion devices. An experimental test system was also established to experimentally validate the model. Two type of refrigerants R-290 and R-22 were involved in the evaluations. The Coefficient of Performance (COP) of the ejector COS-SAC system, exergy destruction, and exergy efficiency were determined and compared with those in the SAC system utilizing capillary tube. The results showed there was a significant improvement in the overall exergy efficiency of the COS-SAC systems. The COP of the COS-SAC system was also found to be better than the COP of the SAC system.
\end{abstract}

\section{Introduction}

One popular utility used to condition the indoor environment to meet the level of human comfort is split air conditioning (SAC) system. Indonesia, as a tropical country, has significant segment on the use of SAC system to bring down the temperature and humidity of the hot and humid air to a comfort zone. This makes the demand of SAC systems continue to increase along with the growth of population and the need for comfort. Most of the SAC systems currently use electricity as the first choice of their energy source. This leads to the intensification of electrical energy use.

Besides that, the SAC system commonly uses vapor compression refrigeration system incorporated capillary tube as the expansion device. The use of capillary tube can cause energy losses

\footnotetext{
* Corresponding author.

E-mail address: nyomansuamir@pnb.ac.id
}

https://doi.org/10.37934/arfmts.77.1.8899 
in the system due to isenthalpic expansion process. Therefore, investigation on the energy conservation technology for SAC system need to be carried out.

Implementation of ejectors to produce constant entropy in the expansion process of refrigeration cycle is one of the energy conservation technologies that can be also applied for SAC system. Some studies of the technologies on refrigeration applications have been reported. Starting with a singlephase ejector on the cooling system resulted in a 7\% to $9 \%$ increase of Coefficient of Performance (COP) for air conditioning (AC) and heat pump uses [1]. Whereas the concept of a two-phase ejector first applied to a cooling system was reported by Gay [2]. Other advantages of two-phase ejectors include: low price, without moving parts, easy construction, and minimum maintenance constraints; these cause the ejectors become attractively prospective in the future $[3,4]$.

The two-phase ejectors applied for refrigeration system could be classified into two types: constant area ejector and constant pressure ejector [5-8]. Physical differences between constant area and constant pressure ejectors have been explained in Keenan et al., [9]. A constant pressure ejector, investigated at the same operating temperature, was reported to have a lower COP values than a system using a constant area ejector [10]. While Ersoy and Bilir Sag [11] reported the results of their theoretical study under off-design conditions on constant area ejector. They found that the systems with a constant area ejector showed an increase in COP value of $22.3 \%$ when compared with the conventional systems. The increase in the COP was depending on the operating conditions. A thermodynamic analysis on refrigeration system incorporated two phase ejector showed that the increase in COP was above $20 \%$, but for experimental study the increase was not more than $10 \%$ [12].

The effects of ejector dimensions, geometric, constant area, and diffuser are currently the most popular research topics. The nozzle dimensions, including convergent and divergent angles and other sizes, commonly refers to the standard from ASHRAE [13]. At the early stage of the application of two-phase ejector for AC units was experimentally investigated as discussed in Ünal [6]. Numerical and experimental investigation of a prototype ejector designed to reduce throttling losses has been reported by Elbel and Hrnjak [14]. The liquid mass could cause inefficiency of about $15 \%$ due to the two-phase flow was difficult to come out properly at each port. Eventually such inefficiency could reduce the system COP. The invention was identified to have limitations due to the use of fluid accumulators or gas separators. Such inefficiency might occur due to the refrigerant flows into the compressor was in a liquid phase. The liquid phase may damage compressors as well as the AC units. Besides that, the size of the accumulator is commonly quite large. When such system is applied for a split AC unit, the installation of the accumulator can become a problem.

This paper presents numerical and experimental investigation results on energy performance and exergy destruction analyses of a Condenser Outlet Split-Split Air Conditioning (COS-SAC) system incorporated dual temperature evaporator at downstream of expansion devices: capillary tube and ejector. Currently, very few researchers work on the dual-temperature evaporator AC ejector system incorporated capillary tube and ejector. Hassanain et al., [15] investigated design and performance of dual-temperature evaporator ejector system for bus application. No researches are published as yet on the application of dual-temperature evaporator ejector on split type air conditioning (SAC) system. The utilization of dual-temperature evaporator can replace the use of liquid accumulator or gas separator. The arrangement without liquid accumulator or gas separator can prevent the emergence of inefficiencies in two-phase ejector refrigeration systems. The ejector, capillary tube and dual-temperature evaporator are found to be properly and nicely fitted in the indoor unit of SAC system to form a tempting COS-SAC system. The paper also presents experimental investigation through a test equipment of the COS-SAC system established for validating the numerical model. HCFC Refrigerant R-22 and hydrocarbon based refrigerant R-290 are considered in the analyses and evaluations. Refrigerant R-290 is substitute of R-22 for SAC applications due to environmental issues. 
R-290, which HCR-22 is one of its trade name, is an environmentally friendly refrigerant and it could perform better than refrigerant R-22 as reported by Aziz et al., [16].

\section{Test Equipment and Methodology}

\subsection{The COS-SAC System and the Two-Phase Ejector}

Figure $1(a)$ and (b) illustrate schematics of the investigated COS-SAC system and P-h diagram of the related vapor refrigeration processes. The COS-SAC system was developed from a conventional SAC system which initially consisted of evaporator, compressor, condenser, and capillary tube as expansion device.

A two-phase flow ejector was added in order to increase the compressor suction pressure and recover the loss of the expansion process in conventional system due to the use of the capillary tube. The original single-temperature evaporator was modified to fit both expansion devices (capillary tube and ejector). The modified evaporator has dual temperature and pressure levels. Thus, the evaporator of the COS-SAC system comprises primary coil at downstream of the ejector where heat is absorbed at higher temperature and pressure (process 6-1) and secondary coil at downstream of the capillary tube where heat is absorbed at lower temperature and pressure (process 7-8).

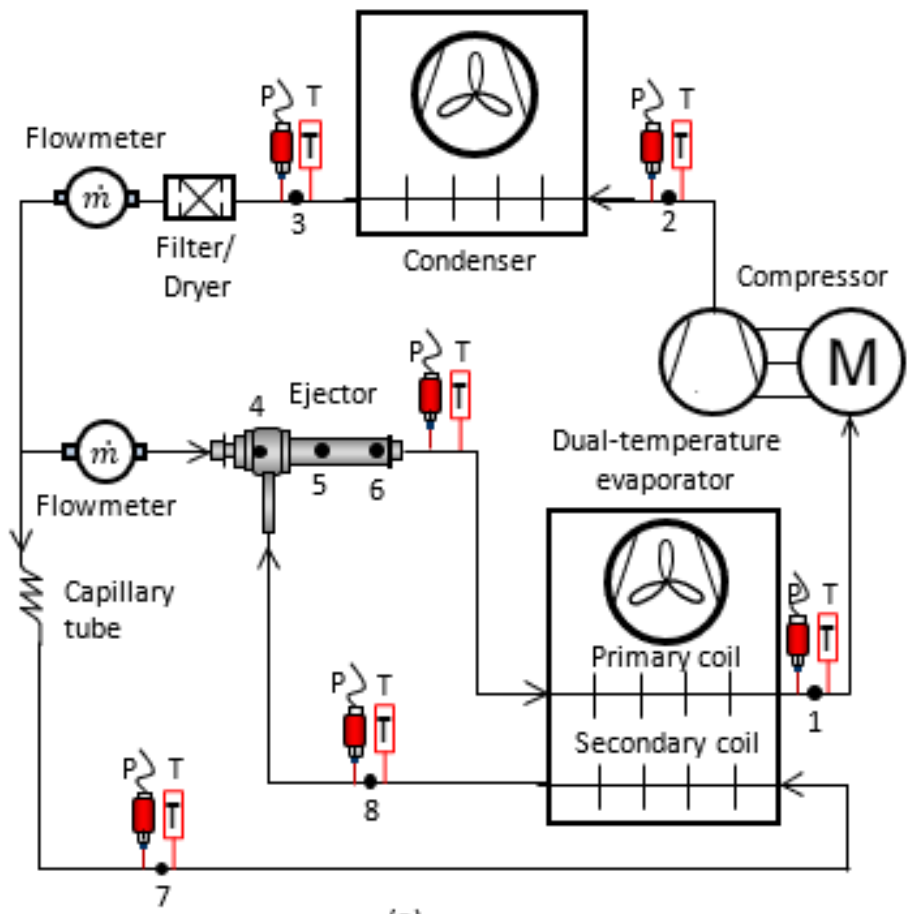

(a)

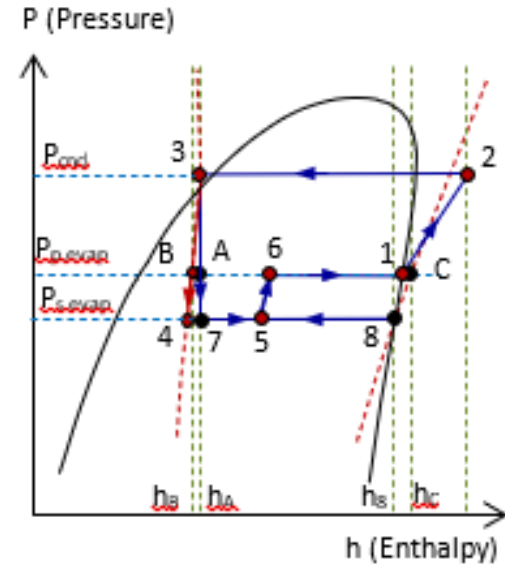

(b)

Fig. 1. The investigated COS-SAC system (a) schematic (b) pressure enthalpy diagram

In the investigated COS-SAC system, as per Figure 1, the compressor compresses the refrigerant from the primary evaporator (state 1) so that the pressure increases, which is then followed by the increase of the refrigerant temperature. The superheated refrigerant exits the compressor (state 2) and flows into the condenser where the process of rejecting heat to the ambient air and condensation occurs. The refrigerant, at high-pressure liquid conditions, exits the condenser (state 3 ) and the flow of refrigerant splits into two liquid streams. The first stream (points 3-4) is primary flow where liquid refrigerant (state 3 ) flows through the ejector and expands in the divergingconvergent nozzle to be a two-phase flow (state 4). The second stream (point 3-7) is secondary flow 
where the liquid refrigerant (state 3 ) passes through the capillary tube and expands to become a twophase mixture conditions (state 7). The two-phase refrigerant from the capillary tube enters the secondary coil of the evaporator and absorbs heat from the load; at the same time the evaporation process occurs. The two-phase primary flow (state 4) and secondary flow in slightly superheated vapor (state 8) mix in the constant area of ejector to become a mixture of state 5 which then flows through the ejector diffuser (state 6) to the primary coil of the evaporator. Heat absorption and evaporation also simultaneously occur in the primary coil evaporator which change the phase and state of the refrigerant from vapor-liquid mixture (state 6) to a superheated vapor (state 1). Then the process repeats to form a complete COS-SAC ejector cycle as shown in Figure 1(b).

\subsection{Experimental Test Setup}

Figure 2 shows the test equipment used for the experiment which comprises a COS-SAC system, instrumentation and data logging system. The equipment was placed in a room where its air temperature was maintained relatively constant at $27^{\circ} \mathrm{C}$. It was also equipped with ducting system incorporated one set electric heater and damper for possibly regulating temperature of the entering air to the condenser. The entering air was kept in the range from $27^{\circ} \mathrm{C}$ up to $37^{\circ} \mathrm{C}$ which represented variation of monthly design dry bulb air temperature in Indonesia [13]. The damper was used to regulate the cooling air flowrate and to simulate the worst case scenario when installation of the outdoor unit could not allow proper ambient air circulation around the unit. To achieve the test conditions, the damper was set at a position such that air flow rate across the condenser of 0.236 $\mathrm{m}^{3} / \mathrm{s}$. It was obtained at average air velocity in the duct of $1.5 \mathrm{~m} / \mathrm{s}$. The average air velocity in the duct was determined using Log-T Method and a hot wire anemometer with $\pm 2 \%$ reading accuracy was used to measure the air velocity. This arrangement could make the test system simulate condensing temperature in the range between $42{ }^{\circ} \mathrm{C}$ and $62^{\circ} \mathrm{C}$.

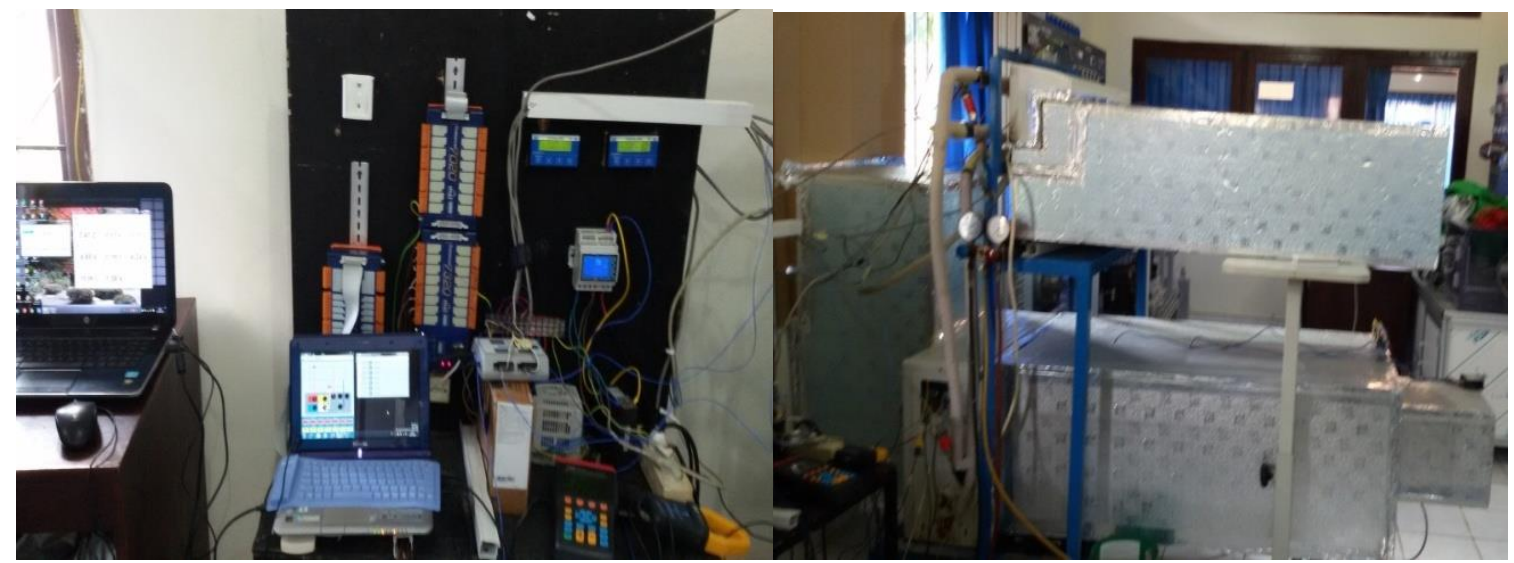

(a)

(b)

Fig. 2. The experimental test equipment (a) instrumentation and data logging systems (b) COSSAC system

The instrumentation system used $\mathrm{K}$ type thermocouples and pressure transmitters as temperature and pressure sensors of accuracy $\pm 1.5{ }^{\circ} \mathrm{C}$ and $\pm 0.8 \%$ respectively. The sensors were connected to a data logging system utilizing Datascan 7320 analog measurement processor and Datascan 7020 analog expansion modules. The data logging system was also equipped with a computer set. The compressor power recorded with a TES 3600 power analyzer of $\pm 1 \%$ accuracy. Two oval gear flow meters were used to measure refrigerant mass flowrates which were installed in 
the main liquid flow at downstream of the condenser and at the primary refrigerant flow before the ejector as shown in Figure 1(a). The flowrate of the refrigerant through the secondary stream could be calculated from the main and the primary stream flowrates. The flow meters have a measurement range from 0.07 - 5 liter per minute; operating pressure from -0.8 bar to 30 bar; and running temperature ranging from $-40{ }^{\circ} \mathrm{C}$ to $90{ }^{\circ} \mathrm{C}$. The accuracy of the flowmeters is $\pm 1.0 \%$ with $0.5 \%$ repeatability of frequency response.

\subsection{Methodology}

Energy and exergy of the COS-SAC system were numerically and experimentally analyzed and evaluated. The experimental investigation was conducted through direct observation and measurement on the COS-SAC test equipment. Firstly, the experimental test was performed for the COS-SAC system using R-22 refrigerant and secondly the test was carried out for the system with R290. Energy and temperature performance parameters were observed and recorded. Points of measurements refer to Figure $1(\mathrm{a})$. The data obtained from the measurement system were processed in a spreadsheet software and simulated in EES (Engineering Equation Solver) program. EES program was also used to process energy and exergy analyses. Energy was analyzed according to the thermodynamics first law (First-LT). Some assumptions were applied which included: negligible pressure loss in the system, isenthalpic expansion process in the capillary tube, mixing process in the constant mixing area of ejector, and steady-state one-dimensional flow.

Isentropic efficiency used to calculate the thermodynamic properties of the compressor output. Empirical expression of the isentropic efficiency of the compressor $\left(\eta_{c m p, i s}\right)$ is given in Eq. $(1)[17,18]$.

$\eta_{c m p, \text { is }}=0.874-(0.0135) P_{i}$

$\mathrm{P}_{\mathrm{i}}=$ the compressor pressure ratio determined by using Eq. (2)

$\mathrm{P}_{\mathrm{i}}=\frac{P_{2}}{P_{1}}$

The isentropic efficiency of the ejector nozzle was obtained from the calculations as reported in Hassanain et al., [15]. The calculations were based on the energy equations at the inlet of the nozzle (point 3) and the outflow (point 4) as shown in Figure 1(a). Then, the equation was used to calculate the thermodynamic properties of the refrigerant on the exit side of the nozzle. The efficiency of the isentropic diffuser was calculated based on the energy equation at points (5) and (6) which was then used to determine the thermodynamic properties of the refrigerant at the diffuser outlet. At the diffuser inlet, the properties of the refrigerant were calculated using energy and efficiency of the mixing part equations (point 4). Mixing efficiency indicates the friction loss in the mixing section.

The entrainment ratio $(\omega)$ is the ratio between the secondary refrigerant mass flowrate entering the ejector $\left(\dot{m}_{8}\right)$ and mass flowrate of the refrigerant at primary inlet ejector $\left(\dot{m}_{4}\right)$. The mass flowrates ( $\dot{\mathrm{m}}_{3}$ and $\dot{\mathrm{m}}_{8}$ ) were obtained from the measurement results (Figure 1(a)). The mass flowrate at primary inlet ejector $\left(\dot{\mathrm{m}}_{4}\right)$ was calculated by using equation $\dot{\mathrm{m}}_{3}=\dot{\mathrm{m}}_{4}+\dot{\mathrm{m}}_{8}$. At the capillary tube, the refrigerant enters at state (3) conditions and exits at point (7), and because isenthalpic process occurs, the enthalpy at point $(7)$ is the same as the enthalpy at point (3). Then the efficiency of the ejector $\left(\eta_{\text {ejr }}\right)$ can be calculated based on Eq. (3) $[6,18]$. 
$\eta_{\text {ejr }}=\omega \frac{h_{C}-h_{8}}{h_{A}-h_{B}}$

The specific enthalpy at state point $A\left(h_{A}\right)$ can be determined by using the temperature and pressure of refrigerant at inlet of the nozzle. While the state point $B\left(h_{B}\right)$ can be obtained from the specific entropy of refrigerant at inlet of the nozzle and the refrigerant pressure at diffuser outlet. The state point $C\left(h_{C}\right)$ is determined by using the diffuser outlet pressure and the specific entropy of the refrigerant at secondary flow inlet (state 8 ).

Exergy, in general, is a quantitative measure of the quality or usefulness of energy, and especially exergy allows comparison based on the same amount (input and output) of various types. Exergy (Ex) is always destroyed in real processes, in part or whole, as explained in Lawrence and Elbel [7]. At each point in the COS-SAC cycle, the specific and physical exergy values are as follows:

$E x=\left(h-h_{0}\right)-T_{0}\left(s-s_{0}\right)$

$\dot{E} x=\dot{m}\left[\left(h-h_{0}\right)-T_{0}\left(s-s_{0}\right)\right]$

$E x_{q}=\left(1-T_{0} / T\right)_{q}$

For constant temperature process of $\mathrm{T}$, the flow of exergy associated with the heat transfer $\mathrm{Q}$ is denoted as Ex , and it can be calculated from Eq. (6). Subscripts "0" indicates a reference parameter and represent environmental pressure and temperature. The environmental pressure and temperature were considered $100 \mathrm{kPa}$ and $27^{\circ} \mathrm{C}$ respectively. These were taken in accordance with Bilir Sag et al., [19]. The equations used to calculate the destruction of exergy and efficiency of the COS-SAC components referred to Dincer and Rosen [20]. The formula used to compute the total amount of exergy destruction (E் $X_{\text {tot }}$ ) is shown in Eq. (7) comprises: the compressor, condenser, evaporator and expansion device exergy destructions which are expressed respectively as E $x_{c m p}$, $\dot{E} x_{\text {cnd }}$ E $x_{\text {evap, }}$ and Ėxthv.

$\dot{E} X_{t o t}=\dot{E} X_{c m p}+\dot{E} x_{c n d}+\dot{E} x_{e v a p}+\dot{E} X_{t h v}$

The overall exergy efficiency $\left(\Psi_{\text {sys }}\right)$ obtained from the ratio of total exergy damage (E் $\left.x_{\text {tot }}\right)$ to total

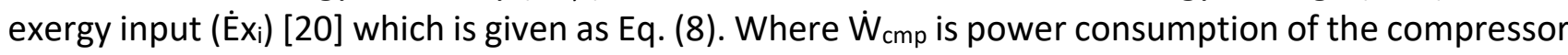

$\Psi_{\text {sys }}=\dot{E} x_{\text {tot }} / \dot{E} x_{i}=1-\left(\dot{E} x_{\text {tot }} / \dot{W}_{c m p}\right)$

\section{Results and Discussion}

\subsection{Energy Analysis}

Energy performance parameters considered in the investigation involve evaporation temperatures of dual-temperature evaporator, ejector efficiency, condensation temperature, cooling capacity, power consumption and COP. The evaporation and condensation temperatures as well as the power consumption were directly observed from the experimental test results.

\subsubsection{Evaporation temperatures}

Figure 3 shows temperature variations of the primary coil and secondary coil evaporators which were tested at room air temperature around $27{ }^{\circ} \mathrm{C}$. The COS-SAC system was charged with R-290 
refrigerant. The evaporation temperature at primary coil varies in the range between $9.3^{\circ} \mathrm{C}$ and 13.0 ${ }^{\circ} \mathrm{C}\left(11.4{ }^{\circ} \mathrm{C}\right.$ in average). Refrigerant leaves the primary coil at temperature ranging from 12.4 to 15.2 ${ }^{\circ} \mathrm{C}$ (average $13.8^{\circ} \mathrm{C}$ ) with degree of superheat at the inlet of the compressor for about $2.4{ }^{\circ} \mathrm{C}$. This indicates that the compressor has worked safely.

The saturation pressure of the primary coil evaporator is in the range between $524 \mathrm{kPa}(\mathrm{g})$ and $593 \mathrm{kPa}(\mathrm{g})$ (76 psig and $86 \mathrm{psig}$ ). It is higher than refrigerant saturation pressure of the secondary coil which is ranging from $469 \mathrm{kPa}(\mathrm{g})$ to $517 \mathrm{kPa}(\mathrm{g})$ ( $68 \mathrm{psig}$ to $75 \mathrm{psig}$ ). Evaporation temperature of the secondary coil fluctuates from $6.1{ }^{\circ} \mathrm{C}$ to $8.8^{\circ} \mathrm{C}$ (at average of $7.8^{\circ} \mathrm{C}$ ). Degree of superheat of the refrigerant leaving the secondary coil is found to vary from 0 to $0.8^{\circ} \mathrm{C}$. This can make a very effective mixture with two phase primary flow exiting the ejector nozzle. The primary and secondary coil evaporation temperatures of $11.4{ }^{\circ} \mathrm{C}$ and $7.8{ }^{\circ} \mathrm{C}$ respectively show that overall temperature evaporation of the COS-SAC system is significantly higher than SAC system which commonly ranges from 4 to $6^{\circ} \mathrm{C}$. Higher evaporation temperature can lead to better energy performance.

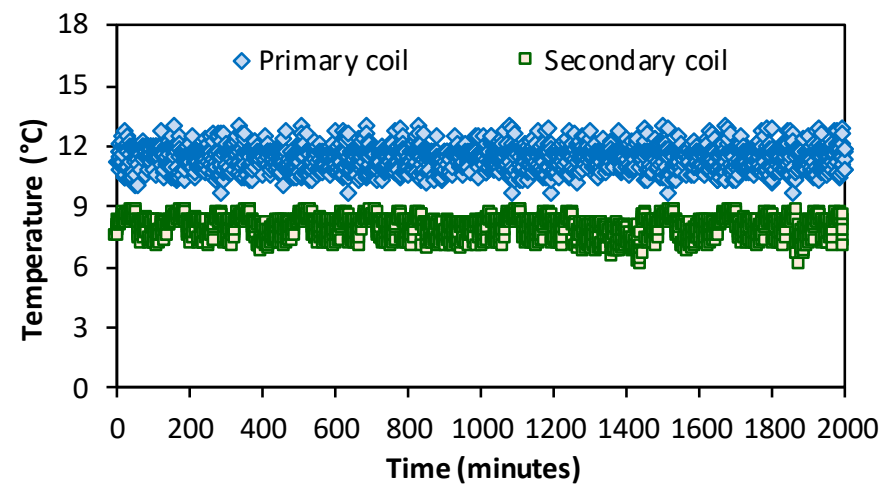

Fig. 3. Saturation temperature of dual-temperature evaporator in the COS-SAC system

\subsubsection{Condensation temperature}

Figure 4 illustrates the influence of condenser temperature on the entrainment ratio. The condensation temperature was varied from 42.3 to $61.6^{\circ} \mathrm{C}$. The entrainment ratio tends to decrease from 0.08 to 0.06 when the condensation temperature increases up to $61.6{ }^{\circ} \mathrm{C}$. The negative correlation between condensation temperature and the entrainment ratio $(\omega)$ also proves the trend. The correlation is given in Eq. (9).

$\omega=-0.0006 T_{\text {cnd }}+0.0999$

Coefficients of determination of the correlation $\left(R^{2}\right)$ is 0.388 which signifies that the correlation is moderate. This implies that the entrainment ratio in the COS-SAC system is acceptably affected by the condensation temperature. Figure 5 shows effects of condenser temperature on the COP and ejector efficiency. The COP of the system decreases from 4.2 to 2.9 when the condensation temperature increases from 42.3 to $61.6^{\circ} \mathrm{C}$ but the ejector efficiency slightly increases from 0.60 to 0.64 . The influence of condensation temperature can be observed through correlation equations as given in Eq. (10).

$\mathrm{COP}=-0.0517 \mathrm{~T}_{\mathrm{cnd}}+6.1203$ 
$\eta_{\text {ejr }}=0.0003 T_{\text {cnd }}+0.6047$

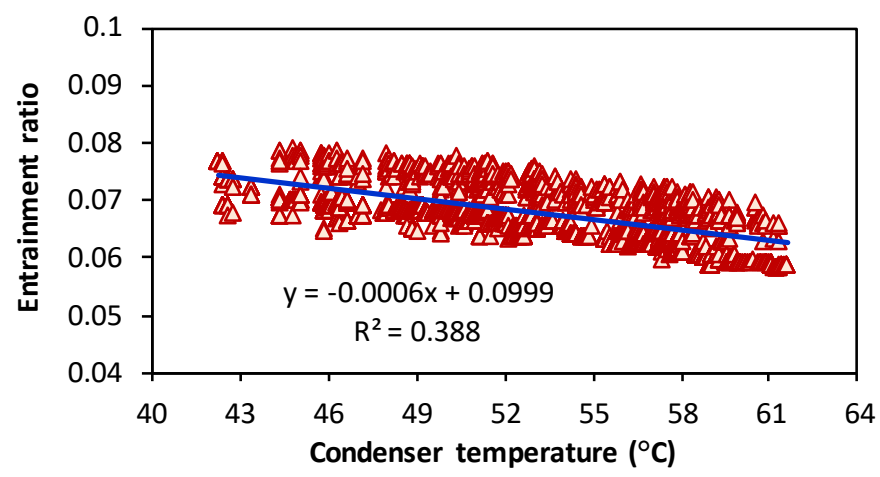

Fig. 4. Effect of condenser temperature on entrainment ratio

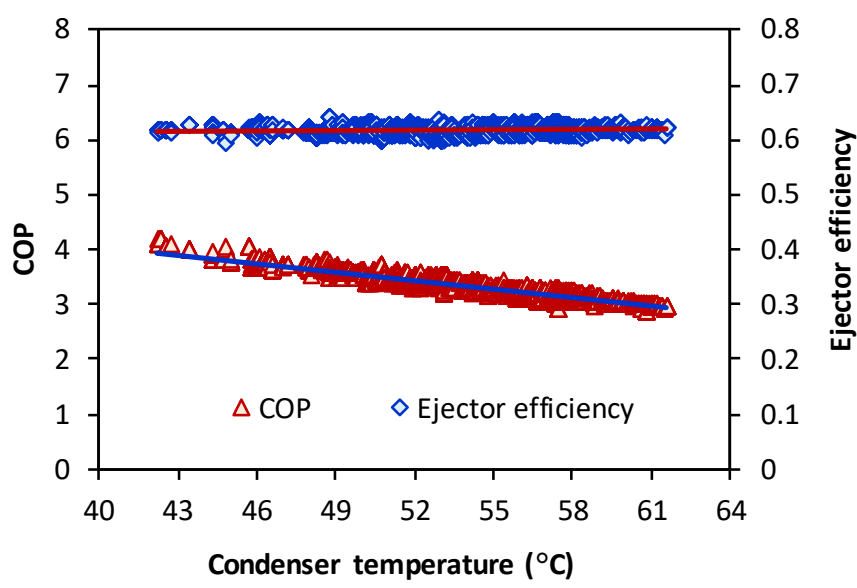

Fig. 5. Effect of condenser temperature on COP and ejector efficiency

The equations confirm a negative relationship between condensation temperature and the COP with strong correlation of determination coefficient $\left(R^{2}\right) 0.908$. Positive but weak correlation is found on the relationship between condensation temperature and ejector efficiency with coefficient of determination 0.027 . The results signify that condensation temperature of the COS-SAC system considerably and negatively affects the COP but have negligible influence on the ejector efficiency.

The efficiency of the ejector can affect the refrigerant flow to the primary evaporator inlet and accordingly can also influence the compressor inlet pressure. Subsequently, the pressure ratio and compression work decrease. This leads to a reduction on input power required to drive the compressor and has a good effect on the COP value of the COS-SAC system.

\subsubsection{Cooling capacity and COP}

Figure 6 shows input power of the compressor in the COS-SAC system charged with R-290, COSSAC with R-22 as well as SAC system with R-22. The investigation was conducted at condensing temperature $43^{\circ} \mathrm{C}$ and room air temperature to be maintained at $27^{\circ} \mathrm{C}$. Power consumptions of the COS-SAC R-290, COS-SAC R-22 and SAC R-22 are respectively $461.9 \mathrm{~W}, 539.6 \mathrm{~W}$ and $540 \mathrm{~W}$. When tested at condensing temperature of $50{ }^{\circ} \mathrm{C}$, then the power consumption of the three systems are found to increase up to $491.9,560$ and $572 \mathrm{~W}$ respectively. Power consumption of the COS-SAC R- 
290 system is $14.4 \%$ lower than COS-SAC charged with R-22 and of about $14.5 \%$ lower than the power of SAC R-22 system. On the other hand, Figure 7 shows that the cooling capacity of the COS-SAC R290 of about $1847.6 \mathrm{~W}$. It drops for about $10.4 \%$ and $2.2 \%$ from the cooling capacity of the COS-SAC R-22 and SAC R-22 respectively. Due to power consumption is much lower, however, the COS-SAC R290 system is found to have a better COP of about $4.7 \%$ higher than the COP of COS-SAC R-22 and of about $14.3 \%$ better than the SAC R-22 system. The COP of the three systems investigated at $43{ }^{\circ} \mathrm{C}$ are found to be 4.0, 3.8, and 3.5 respectively for COS-SAC R-290, COS-SAC R-22 and SAC R-22 systems.

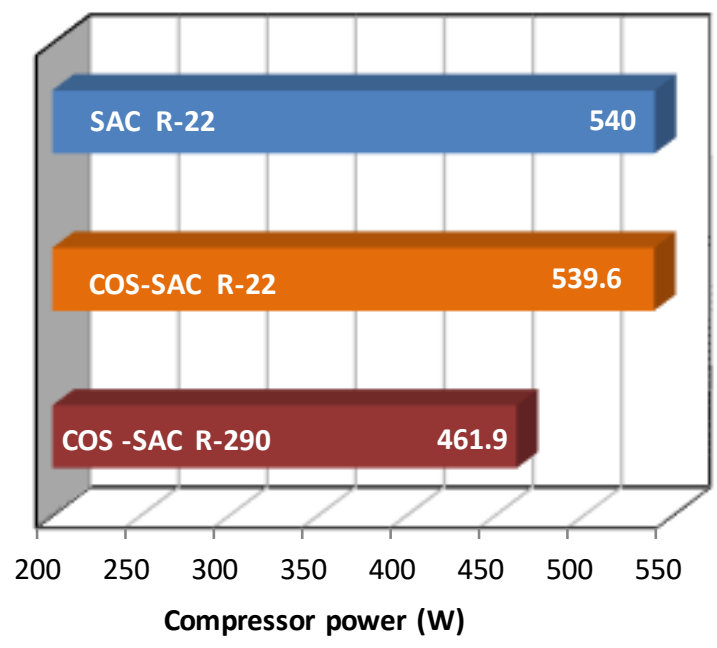

Fig. 6. Compressor power consumption of the COS-SAC R-290, COS-SAC R-22 systems in comparison with SAC R-22 system

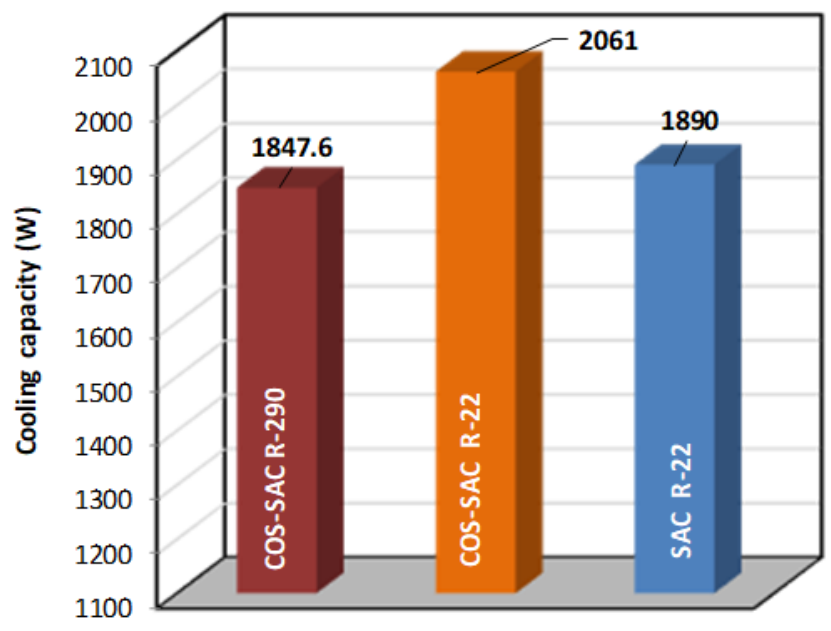

Fig. 7. Cooling capacity of the COS-SAC R-290, COSSAC R-22 systems and compared with SAC R-22 system

These experimental results show that the COPs of the proposed COS-SAC arrangements (COSSAC R-290 and COS-SAC R-22) have exceeded COP of SAC system recommended by ASHRAE of 3.5. The results are found in agreement with Zhang et al., [21] that stated the ejector expander refrigeration cycle (EERC) system with R-32 and R134a could perform better than basic SAC system with COP improvement respectively by $5.22-13.77 \%$ and $6.63-17.83 \%$. The results are also in line with 
Bilir Sag et al., [18] that reported the COP of an ejector expander refrigeration cycle (EERC) R-134a system incorporated accumulator was higher by $7.34-12,87 \%$ than the COP of a basic SAC system and results.

\subsection{Exergy Analysis}

The number of exergy destruction in each component for COS-SAC has been calculated and the results are presented in Table 1 . The values of exergy destruction were simulated at operating conditions: $T_{\text {p.evap }}$ ranging from $9.3-13^{\circ} \mathrm{C}, \mathrm{T}_{\text {s.evap }}$ in the range between $6.1-8.8^{\circ} \mathrm{C}$ and $\mathrm{T}_{\text {cnd }}$ from 42.3 to $61.6^{\circ} \mathrm{C}$. The exergy evaluations were conducted for COS-SAC charging with R-290 (COS-SAC R-290), COS-SAC with refrigerant R-22 (COS-SAC R-22) and SAC system using refrigerant R-22 (SAC R-22). Simulation results as can be seen in Table 1 show that the highest irreversibility or exergy destruction (ED) value of COS-SAC system occurs in the compressor and the lowest value happens in the capillary tube.

Table 1

Exergy destructions (ED) and exergy efficiency of the investigated cycles

\begin{tabular}{lllllll}
\hline \multirow{2}{*}{ Components } & \multicolumn{2}{l}{ SAC R-22 } & \multicolumn{2}{c}{ COS-SAC R-22 } & \multicolumn{2}{c}{ COS-SAC R-290 } \\
\cline { 2 - 7 } & ED (W) & $\begin{array}{l}\text { Exergy } \\
\text { efficiency }\end{array}$ & ED (W) & $\begin{array}{l}\text { Exergy } \\
\text { efficiency }\end{array}$ & ED (W) & $\begin{array}{l}\text { Exergy } \\
\text { efficiency }\end{array}$ \\
\hline Compressor & 290.8 & 0.5145 & 286.4 & 0.5335 & 238.3 & 0.5828 \\
Condenser & 18.59 & 0.8245 & 16.02 & 0.914 & 16.64 & 0.9131 \\
Primary evaporator & 93.86 & 0.2352 & 28.61 & 0.1586 & 21.67 & 0.1747 \\
Secondary evaporator & 0 & 0 & 57.46 & 0.1423 & 47.48 & 0.1713 \\
Throttle device & 39.09 & 0.8996 & 0.5315 & 0.9088 & 1.05 & 0.8932 \\
Ejector & 0 & 0 & 29.45 & 0.9305 & 28.59 & 0.9435 \\
\hline
\end{tabular}

When the ED values of the investigated systems are compared, the exergy destruction that occurs in the capillary tube of the SAC R-22 system is $39.09 \mathrm{~W}$ and the total exergy destruction of the ejector and capillary tube are $29.64 \mathrm{~W}$ and $29.98 \mathrm{~W}$ correspondingly for COS-SAC R-290 and COS-SAC R-22. Therefore, the COS-SAC R-290 and R-22 systems can provide a reduction in exergy destruction by $24.17 \%$ and $23.3 \%$ respectively.

Table 1 also shows exergy efficiency of the investigated systems. It is found that the COS-SAC R290 system can provide better exergy efficiency in almost all of the system components. This certainly leads to a better overall exergy efficiency. The overall exergy efficiencies for COS-SAC R-290 and COSSAC R-22 systems are $23.4 \%$ and $22.5 \%$ which are better than that of the SAC R-22 system which is only $20.6 \%$. The overall exergy efficiency improvements are accounted for $13.9 \%$ and $9.2 \%$ respectively for the COS-SAC R-290 and COS-SAC R-22 systems. These results are found slightly higher than those reported in $[19,21]$.

The improvement on the exergy efficiency of the COS-SAC system can also be observed from Figure 8 which illustrates exergy balance of the three investigated systems using the Grassmann diagram. The COS-SAC R-290 system can provide the highest percentage of exergy output which is accounted for $20.31 \%$. This indicates that the system experiences the smallest total exergy destruction and certainly provide the highest overall exergy efficiency and better COP compared with the other two systems using R-22. This can also provide advantage for the COS-SAC R-290 system because refrigerant R-22 will be phased out in 2030 for Article 5 countries including Indonesia. 


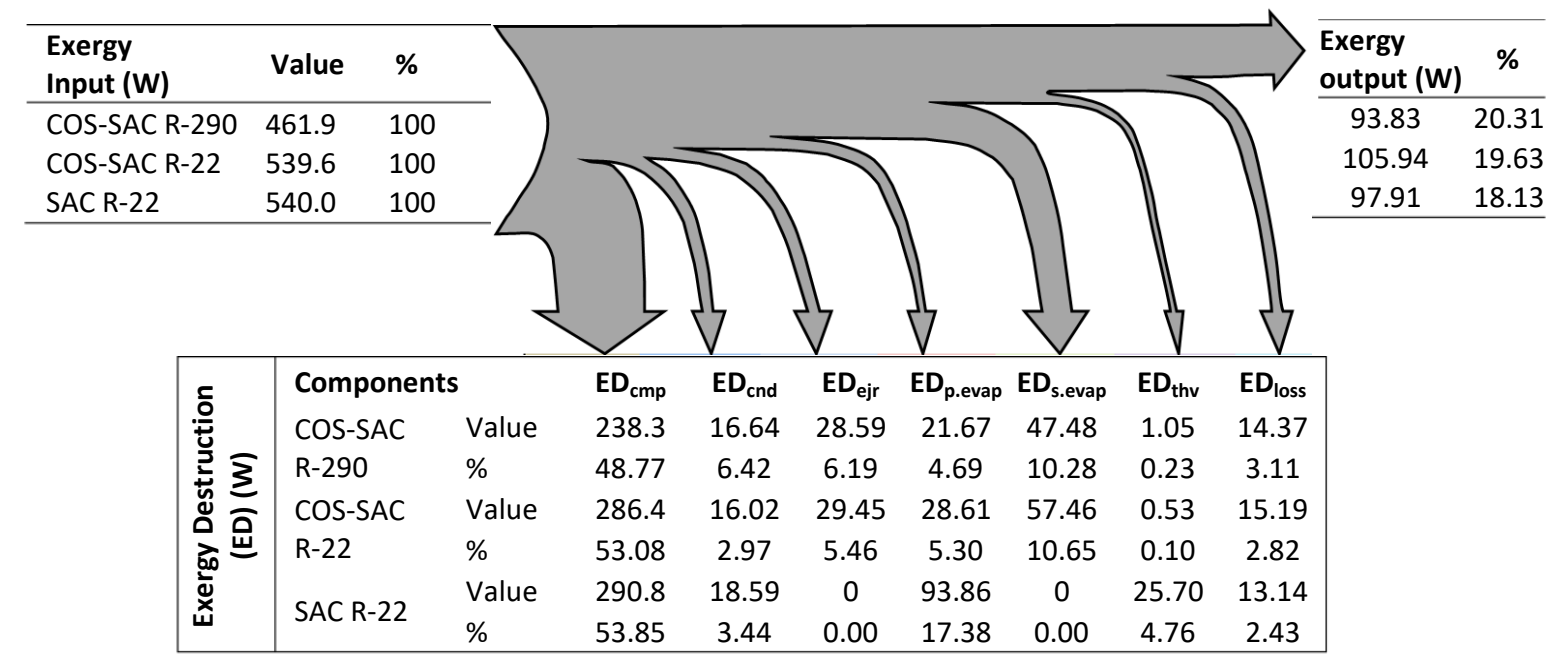

Fig. 8. The exergy balance of the COS-SAC systems in comparison with SAC system

The overall results show that the innovated COS-SAC dual evaporator temperature proposed in this study can eliminate the use of accumulator in the two-phase ejector refrigeration system as well as improve the energy performance of the system. Further investigation will be required on the noise level of the COS-SAC system because noise could reduce efficiency and performance of a split air conditioner system as reported in [22].

\section{Conclusions}

The Condenser Outlet Split-Split Air Conditioning (COS-SAC) system integrated with dualtemperature evaporator and incorporated capillary tube and ejector as expansion devices has been investigated. A numerical model was established to theoretically evaluate the performance COS-SAC system and an experimental test system was also built to experimentally validate the model. Utilization of dual-temperature evaporator eliminated the use of accumulator as it was in previous ejector technology and make the ejector be properly fitted in the indoor unit of the COS-SAC system. The study also found that the COS-SAC system could work at higher evaporation temperature and pressure than SAC system. Energy performance of the COS-SAC system using R-290 were found to be as high as 4.2 which was $4.7 \%$ higher than the COP of COS-SAC charged with R-22 and of about $14.3 \%$ better than the SAC R-22 system. The COS-SAC R-290 and COS-SAC R-22 systems could offer a significant overall exergy efficiency improvement from SAC R-22 system of about $13.9 \%$ and $9.2 \%$.

\section{Acknowledgement}

The authors sincerely thank the Doctorate Program of Udayana University and Mechanical Engineering Department of Bali State Polytechnic for supporting and facilitating this research.

\section{References}

[1] Menegay, Peter, and Alan A. Kornhauser. "Improvements to the ejector expansion refrigeration cycle." In IECEC 96. Proceedings of the 31st Intersociety Energy Conversion Engineering Conference 2, (1996): 702-706.

[2] Gay, Norman H. "Refrigerating system." U.S. Patent 1,836,318, issued December 15, 1931.

[3] Tirmizi, Syed A., Osman K. Siddiqui, P. Gandhidasan, and Syed M. Zubair. "Performance analysis of an ejector cooling system with a conventional chilled water system." Applied thermal engineering 66, no. 1-2 (2014): $113-121$. https://doi.org/10.1016/j.applthermaleng.2014.01.072

[4] Śmierciew, Kamil, Jerzy Gagan, Dariusz Butrymowicz, and Jarosław Karwacki. "Experimental investigations of solar driven ejector air-conditioning system." Energy and buildings $80 \quad$ (2014): $260-267$. https://doi.org/10.1016/i.enbuild.2014.05.033 
[5] Sumeru, K., H. Nasution, and F. N. Ani. "A review on two-phase ejector as an expansion device in vapor compression refrigeration cycle." Renewable and Sustainable Energy Reviews 16, no. 7 (2012): 4927-4937. https://doi.org/10.1016/i.rser.2012.04.058

[6] Ünal, Şaban. "Determination of the ejector dimensions of a bus air-conditioning system using analytical and numerical methods." Applied Thermal $\quad$ Engineering $90 \quad$ (2015): $110-119$. https://doi.org/10.1016/i.applthermaleng.2015.06.090

[7] Lawrence, Neal, and Stefan Elbel. Experimental and analytical investigation of two-phase ejector air-conditioning cycles using low-pressure refrigerants R134a and R1234yf. No. 2013-01-1495. SAE Technical Paper, 2013. https://doi.org/10.4271/2013-01-1495

[8] Lawrence, Neal, and Stefan Elbel. "Theoretical and practical comparison of two-phase ejector refrigeration cycles including First and Second Law analysis." International Journal of Refrigeration 36, no. 4 (2013): 1220-1232. https://doi.org/10.1016/i.ijrefrig.2013.03.007

[9] Keenan, Joseph Henry. "An investigation of ejector design by analysis and experiment." Journal of Applied Mechanics 17 (1950): 299.

[10] Kornhauser, A.A. "The Use of an Ejector as an expander." Proceeding of the 25th Intersociety Energy Conversion Engineering Conference 5 (1990): 79-84.

[11] Ersoy, H. Kursad, and Nagihan Bilir. "The influence of ejector component efficiencies on performance of ejector expander refrigeration cycle and exergy analysis." International Journal of Exergy 7, no. 4 (2010): 425-438. https://doi.org/10.1504/IJEX.2010.033412

[12] Sumeru, Kasni, Shodiya Sulaimon, Henry Nasution, and Farid Nasir Ani. "Numerical and experimental study of an ejector as an expansion device in split-type air conditioner for energy savings." Energy and Buildings 79 (2014): 98 105. https://doi.org/10.1016/i.enbuild.2014.04.043

[13] ASHRAE. (2017). Handbook - Fundamentals (SI). American Society of Heating Refrigerating and Air Conditioning Engineers, 1791 Tullie Circle, N.E., Atlanta.

[14] Elbel, Stefan, and Pega Hrnjak. "Experimental validation of a prototype ejector designed to reduce throttling losses encountered in transcritical R744 system operation." International Journal of Refrigeration 31, no. 3 (2008): 411 422. https://doi.org/10.1016/i.ijrefrig.2007.07.013

[15] Hassanain, M., E. Elgendy, and M. Fatouh. "Ejector expansion refrigeration system: Ejector design and performance evaluation." International Journal of Refrigeration 58 (2015): 1-13. https://doi.org/10.1016/j.ijrefrig.2015.05.018

[16] Aziz, Azridjal, and Afdhal Kurniawan Mainil Thalal. "Effect of Cooling Load on the Performance of R22 Residential Split Air Conditioner when Retrofitted with Hydrocarbon Refrigerant (HCR22)." Journal of Advanced Research in Fluid Mechanics and Thermal Sciences 48: 100-108.

[17] Sarkar, Jahar. "Geometric parameter optimization of ejector-expansion refrigeration cycle with natural refrigerants." International Journal of Energy Research 34, no. 1 (2010): 84-94. https://doi.org/10.1002/er.1558

[18] Nehdi, E., L. Kairouani, and M. Bouzaina. "Performance analysis of the vapour compression cycle using ejector as an expander." International Journal of Energy Research 31, no. 4 (2007): 364-375. https://doi.org/10.1002/er.1260

[19] Sag, N. Bilir, H. K. Ersoy, A. Hepbasli, and H. S. Halkaci. "Energetic and exergetic comparison of basic and ejector expander refrigeration systems operating under the same external conditions and cooling capacities." Energy conversion and management 90 (2015): 184-194. https://doi.org/10.1016/i.enconman.2014.11.023

[20] Dincer, Ibrahim, and Marc A. Rosen. Exergy analysis of heating, refrigerating and air conditioning: methods and applications. Academic Press, 2015. https://doi.org/10.1016/B978-0-12-417203-6.00001-6

[21] Zhang, Zhenying, Lirui Tong, Li Chang, Yanhua Chen, and Xingguo Wang. "Energetic and exergetic analysis of an ejector-expansion refrigeration cycle using the working fluid R32." Entropy 17, no. 7 (2015): 4744-4761. https://doi.org/10.3390/e17074744

[22] Sani, MS Mohd, I. Zaman, and M. M. Rahman. "Analysis of Split Air Conditioner Noise using Sound Intensity Mapping." Journal of Advanced Research in Fluid Mechanics and Thermal Sciences 9, no. 1 (2015): 28-33. 